\title{
Arus Bebas Tenaga Kerja dalam Era Masyarakat Ekonomi ASEAN: Ancaman bagi Indonesia?
}

\author{
Stanislaus Risadi Apresian \\ Universitas Katolik Parahyangan
}

\begin{abstract}
ASEAN Economic Community has been entered into force in December 31st, 2015. A free labour movement is one of major agendas to support the establishment of ASEAN as a single market and production base of ASEAN. This agenda becomes a hot debate since it can be an opportunity or threat for Indonesia. In fact, most of Indonesian people view it as a threat for Indonesia. On the contrary to that view, this research takes a clear position to support that a free labour movement is not a threat for Indonesia. This research is aimed to give a new perspective to see labour market liberalization in ASEAN not as a threat by giving new empirical findings. Theoritically, this research will give new empirical findings to explain that a free labour movement is not a threat for Indonesia by using liberal-institutionalis perspective. Practically, this research will give some policy recommendations addressed to the Government of Indonesia and other stakeholders related to employment issue.
\end{abstract}

Keywords: ASEAN Economic Community, free labour movement, Indonesia

\begin{abstract}
Abstrak
Masyarakat Ekonomi ASEAN sudah berlaku sejak 31 Desember 2015. Arus bebas tenaga kerja menjadi salah satu agenda utama untuk mendukung pembentukan ASEAN sebagai pasar tunggal dan basis produksi. Agenda ini menjadi perdebatan hangat karena agenda tersebut dapat menjadi peluang atau ancaman bagi Indonesia. Pada kenyataanya, sebagian besar masyarakat Indonesia memandangnya sebagai ancaman bagi Indonesia. Bertentangan dengan pendapat tersebut, tulisan ini mengambil posisi yang jelas untuk mendukung bahwa arus bebas tenaga kerja bukan merupakan ancaman bagi Indonesia. Tulisan ini bertujuan untuk memberikan perspektifbaru untuk melihat liberalisasi pasar tenaga kerja ASEAN bukan sebagai ancaman dengan memberikan temuan-temuan baru secara empiris. Secara teori, tulisan ini akan memberikan temuan empiris baru untuk menjelaskan bahwa arus bebas tenaga kerja bukanlah sebuah ancaman bagi Indonesia. Dalam menganalisa kasus ini, tulisan ini akan menggunakan perspektif liberalis-institusionalis. Secara praktek, tulisan ini akan memberikan rekomendasi kebijakan yang ditujukan pada Pemerintah Indonesia dan para pemangku kepentingan yang terkait dengan isu ketenagakerjaan.
\end{abstract}

Kata-kata kunci: Masyarakat Ekonomi ASEAN, arus bebas tenaga kerja, Indonesia 


\section{Pendahuluan}

Indonesia dan kesembilan negara anggota ASEAN sudah memasuki era Masyarakat Ekonomi ASEAN (MEA). MEA sendiri memiliki empat pilar sebagai penopang integrasi ekonomi kawasan yaitu (i) pasar tunggal dan basis produksi, (ii) kawasan perekonomian yang kompetitif, (iii) pembangunan ekonomi yang merata, dan (iv) integrasi kedalam perekonomian global (Plummer, Petri, dan Zhai, 2014, P. 4). Arus bebas tenaga kerja merupakan salah satu agenda utama dalam proses integrasi ekonomi ASEAN untuk mewujudkan pilar yang pertama yaitu pasar tunggal dan basis produksi. Arus bebas tenaga kerja merupakan komponen penting di samping arus bebas barang, jasa, dan investasi. Dalam MEA, ada beberapa profesi yang dapat bergerak secara bebas. Sampai pada awal tahun 2016 sudah ada delapan profesi yang memiliki mutual recognition agreement (MRA) pada level ASEAN. Kedelapan profesi tersebut antara lain: jasa teknik/ insinyur (2005), dokter gigi, perawat (2006), arsitek (2007), tenaga survei (2007), akuntan (2009), praktisi kesehatan (2009), dan tenaga profesional di bidang pariwisata (2012). Kesepakatan arus bebas tenaga kerja tidak hanya berhenti pada delapan profesi itu saja. Kesepakatan baru antar-negara anggota ASEAN dapat menambah profesi lain yang dapat bergerak bebas di kawasan ASEAN melalui MRA.

MRA sendiri merupakan sebuah langkah strategis yang coba diupayakan oleh ASEAN untuk memfasilitasi tenaga kerja agar keahlian dan ketrampilannya diakui oleh negara anggota ASEAN yang lain. Selama ini tenaga kerja sudah memiliki keahlian maupun keterampilan, namun negara tujuan di mana mereka ingin bekerja tidak memiliki mekanisme atau standar yang sama dengan negara asal dalam penentuan sertifikasi keahlian dan keterampilan tersebut (Sugiyarto dan Agunias, 2014). MRA yang disepakati oleh negara anggota ASEAN membuat keahlian dan keterampilan tenaga kerja diakui kualifikasinya di seluruh negara anggota ASEAN.

MEA sudah berlaku dan tidak bisa dihindari lagi meskipun banyak kalangan yang beranggapan bahwa tenaga kerja Indonesia belum siap menghadapi persaingan di ASEAN. Siap atau tidak siap MEA tetap berlaku. Masyarakat Indonesia harus memasuki era MEA sebagai konsekuensi dari hasil kesepakatan para elit ASEAN pada 2007 yang tertuang dalam Piagam ASEAN.

Dalam menanggapi agenda arus bebas tenaga kerja tersebut, pendapat masyarakat, praktisi, dan kalangan akademisi terbagi menjadi dua. Ada pihak yang menganggap arus bebas tenaga kerja sebagai sebuah ancaman, sementara ada pula pihak yang menganggap sebagai peluang bagi tenaga kerja Indonesia.

Tulisan ini mengambil posisi pada pendapat yang kedua. MEA bukanlah sebuah ancaman bagi ketenagakerjaan Indonesia, kekhawatiran 
terhadap ASEAN muncul lebih disebabkan karena pengetahuan masyarakat Indonesia tentang MEA belum mendalam. Masyarakat Indonesia tidak perlu mengalami kekhawatiran yang berlebihan terhadap MEA. Peluang yang ditawarkan dengan adanya agenda arus bebas tenaga kerja lebih besar dibandingkan kerugian yang mungkin dialami oleh Indonesia. Mengacu pada permasalahan di atas, penulisan artikel ini berdasar pada satu pertanyaan penelitian yang utama yaitu sejauh mana agenda arus bebas tenaga kerja dalam MEA ini dapat mempengaruhi kondisi ketenagakerjaan domestik Indonesia?

Tujuan utama dari tulisan ini adalah memberikan perspektif baru dalam melihat era arus bebas tenaga kerja ASEAN sebagai peluang dan bukan ancaman bagi pasar tenaga kerja Indonesia dengan bukti-bukti empiris. Tulisan ini penting karena saat ini anggapan bahwa MEA menjadi ancaman bagi ketenagakerjaan Indonesia lebih dominan di kalangan masyarakat Indonesia. Kekhawatiran ini dapat menimbulkan sikap pesimis terhadap MEA bahkan pada tingkatan yang lebih ekstrim dapat menimbulkan sikap anti tenaga kerja asing. Optimisme dalam menghadapi arus bebas tenaga kerja ASEAN dengan melihat peluang-peluang yang ada harus dibangun untuk menimbulkan kepercayaan diri tenaga kerja Indonesia dalam bersaing di pasar tenaga kerja ASEAN.

Tulisan ini terbagi menjadi enam bagian utama. Pada awal tulisan dijelaskan mengenai latar belakang, tujuan penulisan, signifikansi, dan permasalahan. Selanjutnya tulisan ini membahas mengenai dua pendekatan utama yang sering digunakan dalam memandang fenomena arus bebas tenaga kerja di ASEAN yaitu neo-merkantilis dan liberal institusionalis. Dalam menganalisa isu arus bebas tenaga kerja di ASEAN, pendekatan yang digunakan dalam tulisan ini adalah liberal-institusionalis. Bagian selanjutnya menjelaskan mengenai kondisi umum ketenagakerjaan Indonesia dalam lingkup ASEAN. Setelah itu, tulisan akan memaparkan analisa apakah arus bebas tenaga kerja ASEAN menjadi ancaman atau bukan dan memberikan penjelasan tambahan bahwa integrasi ASEAN harus dilihat sebagai sebuah kolaborasi bukan kompetisi. Tulisan ini diakhiri dengan kesimpulan dan rekomendasi kebijakan.

\section{Dua Pendekatan yang Berbeda dalam Memandang MEA}

Dalam memandang proses integrasi ekonomi ASEAN, setidaknya ada dua perspektif strategi geopolitik yang menjadi arus utama yang kemudian melahirkan perdebatan mengenai kehadiran MEA sebagai ancaman atau bukan bagi ketenagakerjaan Indonesia. Kedua strategi geopolitik tersebut adalah pemikiran neo-merkantilis dan liberalinstitusionalis, dimana kedua perspektif ini memandang MEA dengan cara yang sangat berbeda. 


\section{Perspektif Neo-merkantilis}

Dalam era liberalisasi, interdependensi negara-negara di dunia semakin meningkat. Liberalisasi tenaga kerja yang menjadi salah satu agenda utama dalam MEA juga meningkatkan interdependensi negara-negara anggota ASEAN. Perspektif neo-merkantilis memandang bahwa liberalisasi tenaga kerja ini menimbulkan dilema tersendiri bagi negara-negara anggota ASEAN. Pada satu sisi, negara-negara ASEAN sudah menyepakati pembentukan MEA untuk mendorong integrasi ekonomi kawasan. Namun di sisi lain ada kekhawatiran negaranya akan dibanjiri tenaga kerja asing dari negara ASEAN lainnya yang merebut pasar tenaga kerja lokal. Tidak terkecuali Indonesia juga menghadapi dilema semacam ini. Salah satu alasannya adalah ketidaksiapan tenaga kerja Indonesia untuk bersaing pada level ASEAN.

Perspektif neo-merkantilis ini memandang bahwa interdependensi antarnegara tidak selalu simetris (Balaam dan Veseth, 2001, P. 32). Maksud dari pandangan ini adalah selalu ada kemungkinan suatu negara lebih bergantung kepada negara lain. Dalam isu ketenagakerjaan di ASEAN, dimana sudah dimulai arus bebas tenaga kerja, ada ancaman bahwa akan banyak tenaga kerja ahli dari negara ASEAN lain yang masuk ke Indonesia. Sementara itu, tenaga kerja Indonesia belum siap bersaing dengan keahlian yang dimiliki. Hal ini dikhawatirkan akan membuat pasar tenaga kerja domestik Indonesia bergantung terhadap suplai tenaga kerja asing dari negara tetangga. Menurut pandangan neo-merkantilis, secara ideal hanya self-sufficiency yang dapat membuat suatu negara aman secara politik dan ekonomi (Balaam dan Veseth, 2001, P. 33).

Pandangan perspektif neo-merkantilis ini kemudian menganggap tenaga kerja asing dari negara anggota ASEAN lain merupakan ancaman bagi pasar tenaga kerja domestik. Pandangan seperti ini biasanya mendukung kebijakan-kebijakan untuk menghambat arus masuk tenaga kerja asing, jangan sampai pasar tenaga kerja domestik dibanjiri tenaga kerja asing sehingga merugikan kepentingan nasional untuk mengurangi angka pengangguran.

Persaingan geopolitik pada saat ini tidak ada bedanya dengan geopolitik seribu tahun yang lalu. Negara bangsa selalu bersaing untuk mendapatkan pengaruh dan power yang pada akhirnya hanya menciptakan satu pemenang (Mahbubani, 2013,: 146). Perspektif ini mendorong para pembuat kebijakan untuk berkompetisi dengan negara lain.

Apabila perspektif neo-merkantilis ini diaplikasikan untuk memandang liberalisasi pasar tenaga kerja ASEAN, maka para pembuat kebijakan akan memandang liberalisasi pasar tenaga kerja sebagai ancaman bagi pasar tenaga kerja domestik. Liberalisasi tersebut akan membawa negara-negara ASEAN pada zero sum game dimana antarnegara akan saling 
berkompetisi dan akan ada pihak yang menang dan kalah. Menang dalam artian mampu mengambil keuntungan dari liberalisasi pasar tenaga kerja dan kalah dalam artian mengalami kerugian dari liberalisasi pasar tenaga kerja. Perspektif neo-merkantilis dapat mempengaruhi para pembuat kebijakan untuk meminimalisir dampak negatif dengan membuat regulasi yang dapat menghambat arus masuk tenaga kerja asing. Tujuannya adalah mencegah negara lain untuk mengambil keuntungan dari pasar tenaga kerja domestik. Perspektif ini memandang pesimis arus bebas tenaga kerja di ASEAN dapat menguntungkan semua negara.

\section{Perspektif Liberal-Institusionalis}

Perspektif liberalisme memandang sifat dasar manusia adalah baik yaitu cinta damai, kooperatif, kompetitif dengan cara yang konstruktif, dan melakukan sesuatu berdasarkan suatu alasan bukan hanya emosi (Balaam dan Veseth, 2001,: 48). Secara garis besar perspektif ini melihat sifat dasar manusia dalam konteks positif bahwa manusia dapat bekerja sama untuk mencapai suatu tujuan tertentu. Bertolak belakang dengan perspektif sebelumnya, menurut perspektif liberalisme kontestasi geopolitik bisa menjadi sebuah win-win game. Dengan kerja sama antarnegara, zero sum game dapat berubah menjadi win-win game (Mahbubani, 2013,: 145). Perspektif ini mendorong para pembuat kebijakan negara-negara di ASEAN untuk meningkatkan kerjasama dan kolaborasi dengan negara lain.

Apabila kita mengaplikasikan perspektif ini dalam memandang fenomena liberalisasi pasar tenaga kerja di ASEAN, ada suatu optimisme bahwa negara-negara anggota ASEAN dapat bekerja sama untuk memanfaatkan pasar tenaga kerja yang terbuka untuk kemajuan bersama. Meskipun ada persaingan dalam pasar tenaga kerja, para aktor yang terlibat akan bersaing dengan cara yang konstruktif tidak seperti apa yang dilakukan oleh pengambil kebijakan yang dipengaruhi oleh perspektif realis misalnya membuat regulasi yang membatasi jumlah atau menghambat masuknya tenaga kerja asing.

\section{Kondisi Ketenagakerjaan Indonesia dalam Lingkup ASEAN}

Indonesia memiliki angkatan kerja terbesar di ASEAN. Pada tahun 2015 jumlah angkatan kerja Indonesia mencapai 128,30 juta jiwa (BPS, 2015). Jumlah tersebut sangat signifikan mengingat jumlah penduduk ASEAN mencapai sekitar 616.614.000 jiwa pada tahun 2012 (ACIF, 2013). Jumlah angkatan kerja Indonesia sekitar $20 \%$ dari total jumlah pendudukASEAN. Untuk lebih jelasnya berikut adalah perbandingan jumlah angkatan kerja Indonesia dengan negaranegara ASEAN. 
Tabel 1. Perbandingan Angkatan Kerja Negara Anggota ASEAN

\begin{tabular}{|l|l|}
\hline Negara & Jumlah Angkatan Kerja \\
\hline Indonesia & 118.193 \\
\hline Vietnam & 53.246 \\
\hline Filipina & 41.022 \\
\hline Thailand & 39.398 \\
\hline Myanmar & 30.121 \\
\hline Malaysia & 13.785 \\
\hline Kamboja & 7.400 \\
\hline Singapura & 3.444 \\
\hline Laos & 3.080 \\
\hline Brunei Darussalam & 186 \\
\hline
\end{tabular}

Sumber: ILO dan ADB

Apabila dibandingkan dengan negara anggota ASEAN yang lain, tenaga kerja Indonesia dapat dikatakan yang paling agresif dalam pasar tenaga kerja ASEAN. Banyak sekali tenaga kerja Indonesia yang bekerja di negara anggota ASEAN. Menurut data dari Direktur Jenderal Pembinaan Penempatan Tenaga Kerja (Ditjen Binapenta), ada empat negara yang menjadi tujuan utama Tenaga Kerja Indonesia yaitu Malaysia, Singapura, Brunei Darussalam, dan Thailand.

Tabel 2. Penempatan Tenaga Kerja Indonesia di Malaysia, Singapura, Brunei Darussalam, dan Thailand 2012-2014

\begin{tabular}{|c|l|l|l|l|l|}
\hline No. & \multicolumn{1}{|c|}{ Negara } & \multicolumn{1}{|c|}{$\mathbf{2 0 1 2}$} & \multicolumn{1}{|c|}{$\mathbf{2 0 1 3}$} & \multicolumn{1}{|c|}{$\mathbf{2 0 1 4}$} & \multicolumn{1}{c|}{$\mathbf{2 0 1 5}$} \\
\hline 1 & Malaysia & 134.069 & 150.250 & 127.827 & 97.635 \\
\hline 2 & Singapura & 41.556 & 34.655 & 31.680 & 20.895 \\
\hline 3 & Brunei Darussalam & 13.593 & 15.374 & 11.848 & 5.501 \\
\hline 4 & Thailand & 1.035 & 1.041 & 717 & 90 \\
\hline
\end{tabular}

Melihat angka tersebut, sepertinya tidak hanya Indonesia yang cemas dengan liberalisasi pasar tenaga kerja. Negara anggota ASEAN lainnya tentunya mengalami kecemasan yang sama yang dialami oleh Indonesia terlebih kekuatan tenaga kerja Indonesia sangat diperhitungkan dalam pasar tenaga kerja ASEAN karena Indonesia menyediakan supply tenaga kerja dalam jumlah yang besar. 
Jumlah Tenaga Kerja Asing (TKA) yang masuk ke Indonesia juga cukup banyak, tetapi tidak sebanyak TKI yang mengisi pasar tenaga kerja ASEAN. Tenaga kerja asing yang bekerja di Indonesia paling banyak bukan berasal dari negara-negara ASEAN melainkan berasal dari Republik Rakyat Tiongkok disusul Jepang dan India. Malaysia menempati urutan keempat TKA terbesar di Indonesia, diikuti Thailand dan Filipina di posisi ketujuh dan kesembilan. Berikut adalah data TKA dari Malaysia, Thailand, dan Filipina. Data TKA dari keenam negara ASEAN lainnya tidak dicantumkan karena jumlahya kurang signifikan.

Tabel 3. TKA dari Malaysia, Thailand, dan Filipina tahun 2011-2014

\begin{tabular}{|c|c|c|c|c|c|}
\hline No. & Negara & 2011 & 2012 & 2013 & 2014 * \\
\hline 1 & Malaysia & 4.938 & 5.330 & 4.962 & 3.779 \\
\hline 2 & Thailand & 3.836 & 4.146 & 1.841 & 941 \\
\hline 3 & Filipina & 3.816 & 3.292 & 2.631 & 2.092 \\
\hline
\end{tabular}

Sumber: Dit PPTKA - Ditjen Binapenta, 2014

Memang lebih banyak tenaga kerja Indonesia yang keluar negeri dari pada jumlah tenaga kerja asing yang masuk ke Indonesia, namun perlu dilihat sebaran menurut level jabatan atau jenis pekerjaan. Sebaran TKA di Indonesia didominasi oleh jabatan profesional, advisor/konsultan, manajer, direksi, supervisor, teknisi, dan komisaris. Indonesia sendiri masih memiliki permasalahan dalam peningkatan daya saing tenaga kerja. Salah satu hal yang nampak misalnya jumlah tenaga kerja yang tersertifikasi di Indonesia masih sangat minim. Tahun 2014 hanya ada sekitar 2,1 juta tenaga kerja yang sudah tersertifikasi (Widianto, 2014).

\section{Masyarakat Ekonomi ASEAN: Ancaman bagi Tenaga Kerja Indonesia?}

Survei tatap muka yang dilakukan oleh Bidang Penelitian dan Pengembangan (Litbang) Kompas pada tahun 2015 dapat menggambarkan persepsi masyarakat Indonesia secara umum terhadap pemberlakuan MEA. Survei tersebut menggambarkan bahwa sebagian besar masyarakat Indonesia memandang MEA merugikan bagi Indonesia. Perbandingannya sangat mencolok, hanya satu responden dari delapan responden yang menilai MEA lebih menguntungkan bagi Indonesia (Kompas, 2015). Hal ini menunjukkan hanya sedikit masyarakat yang melihat MEA sebagai keuntungan bagi Indonesia. Survei tersebut menunjukkan bahwa ada kekhawatiran berlebihan yang dialami oleh masyarakat Indonesia. Litbang Kompas menyebutkan bahwa kekhawatiran tersebut muncul kare- 
na kurangnya sosialisasi yang diberikan kepada masyarakat, bahkan dari survei tersebut terlihat bahwa dua dari lima responden tidak mengenal apa itu MEA. Kekhawatiran tersebut merupakan suatu hal yang wajar, ketika seseorang menghadapi sesuatu yang baru dan tidak mengetahui secara jelas apa yang dihadapinya maka rasa khawatir akan muncul. Pemahaman masyarakat Indonesia mengenai MEA memang masih kurang sehingga menganggap MEA akan merugikan Indonesia.

Survei partisipasi publik yang diselenggarakan oleh International NGO Forum on Indonesian Development (INFID) juga memberikan gambaran kurangnya pengetahuan masyarakat Indonesia terhadap ASEAN. Hasil survei INFID menunjukkan bahwa partisipasi warga sangat minim, lebih dari $70 \%$ warga Indonesia merasa tidak terlibat dalam penentuan kebijakan dan program ASEAN. Berikut adalah data hasil survei berupa lima pertanyaan yang diselenggarakan oleh INFID (INFID, 2015, p. 28).

Grafik 1. Partisipasi Publik di ASEAN Menurut Warga

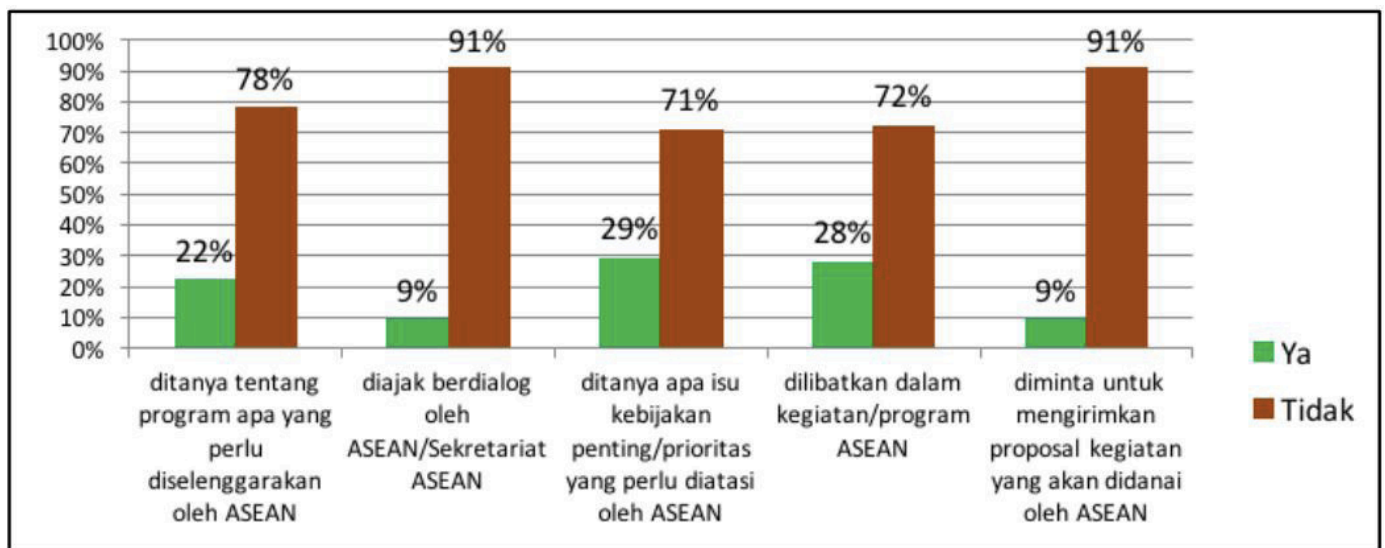

Sumber: INFID, 2015

Melihat kondisi saat ini, liberalisasi pasar tenaga kerja memang lebih dianggap sebagai ancaman oleh sebagian masyarakat Indonesia. Kekhawatiran yang biasanya muncul antara lain kekhawatiran akan serbuan tenaga kerja dari negara anggota ASEAN ke Indonesia, peluang bekerja menjadi semakin kecil karena lapangan tenaga kerja di Indonesia masih kurang, tenaga ahli akan didominasi oleh tenaga kerja asing, dan pengangguran menjadi semakin tinggi. Inti dari kekhawatiran tersebut adalah kesadaran masih lemahnya daya saing tenaga kerja Indonesia. Apa yang menjadi kekhawatiran terkait daya saing tenaga kerja Indonesia memang nyata. Daya saing tenaga kerja Indonesia secara umum memang berada di bawah negara anggota ASEAN lain seperti Singapura, Malaysia, dan Thailand. 
Salah satu indikator untuk mengukur tingkat daya saing tenaga kerja adalah tingkat pendidikannya. Angkatan kerja Indonesia memang sangat besar tetapi apabila dilihat tingkat pendidikannya, sebagian besar tingkat pendidikannya masih rendah yakni lulusan tingkat Sekolah Dasar (SD).

Tabel 4. Jumlah Angkatan Kerja Berdasarkan Jenjang Pendidikan

\begin{tabular}{|l|l|l|}
\hline Jenjang Pendidikan & $\begin{array}{l}\text { Jumlah Angkatan Kerja } \\
\text { (juta) }\end{array}$ & Jumlah Dalam Persen \\
\hline SD & 56,66 & 44,16 \\
\hline SMP & 23,12 & 18,02 \\
\hline SMA & 21,57 & 16,81 \\
\hline SMK & 12,97 & 10,11 \\
\hline Diploma I/II/III & 3,39 & 2,65 \\
\hline Universitas & 10,59 & 8,25 \\
\hline
\end{tabular}

Sumber: BPS, Berita Resmi Statistik Mei 2015, Diolah Pusdatinaker

Tabel di atas dapat menggambarkan komposisi angkatan kerja berdasarkan jenjang pendidikan. Pada tahun 2015, 44,16 \% angkatan kerja Indonesia pendidikannya adalah lulusan SD dan jumlahnya mencapai 56,66 juta jiwa. Angkatan kerja yang sudah memiliki keahlian secara formal yaitu lulusan SMK, diploma, dan universitas jumlahnya hanya 21,01\% dari total angkatan kerja.

Indikator lain untuk mengetahui tingkat daya saing dalam pasar tenaga kerja adalah angka melek huruf, rata-rata penghasilan perbulan, dan produktivitas tenaga kerja. Berikut adalah data perbandingan indikator pasar tenaga kerja negara-negara ASEAN.

Tabel 5. Beberapa Indikator Pasar Tenaga Kerja ASEAN

\begin{tabular}{|l|l|l|l|}
\hline \multicolumn{1}{|c|}{ Negara } & $\begin{array}{c}\text { Angka Melek } \\
\text { Huruf (\%) }\end{array}$ & $\begin{array}{l}\text { Rata-rata Gaji } \\
\text { Per Bulan (\$) }\end{array}$ & $\begin{array}{c}\text { Produktivitas } \\
\text { Tenaga Kerja } \\
\text { constant 2005 } \\
\text { International (\$) }\end{array}$ \\
\hline Indonesia & 92,8 & 174 & 9.848 \\
\hline Vietnam & 93,4 & 181 & 5.440 \\
\hline Filipina & 95,4 & 206 & 10.026 \\
\hline Thailand & 93,5 & 357 & 14.754 \\
\hline
\end{tabular}




\begin{tabular}{|l|l|l|l|}
\hline Myanmar & 92,7 & - & 2.828 \\
\hline Malaysia & 93,1 & 609 & 35.751 \\
\hline Kamboja & 73,9 & 121 & 3.989 \\
\hline Singapura & 95,9 & 3.547 & 98.072 \\
\hline Laos & 72,7 & 119 & 5.396 \\
\hline $\begin{array}{l}\text { Brunei } \\
\text { Darussalam }\end{array}$ & 95,4 & 181 & 100.015 \\
\hline
\end{tabular}

Sumber: ILO dan ADB

Angka melek huruf tenaga kerja Indonesia masih kalah dengan Singapura, Brunei Darussalam, Filipina, Thailand, Malaysia, dan Vietnam. Penghasilan tenaga kerja Indonesia dan tingkat produktivitasnya juga di bawah penghasilan rata-rata dari Singapura, Malaysia, Thailand, Filipina, Brunei Darussalam, dan Vietnam.

Tabel 6. Peringkat Human Development Index Negara Anggota ASEAN

\begin{tabular}{|l|l|l|}
\hline No. & Negara & Peringkat 2014 \\
\hline 1. & Singapura & 11 \\
\hline 2. & Brunei Darussalam & 31 \\
\hline 3. & Malaysia & 62 \\
\hline 4. & Thailand & 93 \\
\hline 5. & Indonesia & 110 \\
\hline 6. & Filipina & 115 \\
\hline 7. & Vietnam & 116 \\
\hline 8. & Laos & 141 \\
\hline 9. & Kamboja & 143 \\
\hline 10. & Myanmar & 148 \\
\hline
\end{tabular}

Sumber: UNDP

Selain itu, apabila dilihat dari indeks pembangunan manusia, Indonesia berada pada urutan kelima di ASEAN. Indeks pembangunan manusia Indonesia masih kalah dengan Singapura, Brunei Darussalam, Malaysia, dan Thailand. Bahkan Indonesia tidak masuk dalam peringkat 100 besar indeks pembangunan manusia.

Meskipun secara umum daya saing tenaga kerja Indonesia masih kalah dibandingkan beberapa negara ASEAN yang lain, Indonesia masih memiliki peluang untuk mengambil keuntungan dari adanya liberalisasi pasar tenaga kerja ASEAN. Kekhawatiran terhadap serbuan tenaga kerja 
dari negara ASEAN lain sepertinya tidak perlu dibesar-besarkan. Tidak semudah itu tenaga kerja asing dari ASEAN bebas masuk ke Indonesia. Meskipun ada kata 'bebas' tentunya tetap ada regulasi yang mengatur keluar masuknya tenaga kerja asing ke Indonesia. Sugiyarto dan Agunias (2014) juga menjelaskan bahwa negara anggota ASEAN bertujuan untuk memfasilitasi arus bebas tenaga kerja terampil yang benar-benar tidak ada larangan sama sekali. MEA hanya memfasilitasi pergerakan tenaga kerja terampil ini agar lebih mudah untuk diterima di negara anggota ASEAN yang lain.

Hal mendasar yang perlu diketahui oleh masyarakat adalah hanya tenaga terampil yang boleh menikmati kebijakan arus bebas tenaga kerja di ASEAN yang didukung oleh adanya MRA. Tenaga kerja terampil yang dimaksud saat ini hanya delapan profesi yang sudah disepakati dalam MRA yang ditandatangani oleh negara anggota ASEAN. Kedelapan profesi tersebut adalah jasa teknik/ insinyur (2005), dokter gigi, perawat (2006), arsitek (2007), tenaga survei (2007), akuntan (2009), praktisi kesehatan (2009), dan tenaga profesional di bidang pariwisata (2012). Selain kedelapan profesi tersebut, regulasi keluar masuk tenaga kerja masih diatur dengan regulasi yang lama sesuai kebijakan masing-masing negara. Jadi sangat kecil kemungkinan tenaga kerja asing merebut peluang kerja domestik selain kedelapan profesi tersebut.

Saat ini ada delapan profesi yang sudah memiliki MRA. Tidak menutup kemungkinan jumlah profesi yang akan memiliki bertambah seiring berjalannya waktu. Meskipun sudah memiliki MRA, tidak otomatis tenaga kerja yang masuk dalam MRA bisa bebas keluar masuk negara ASEAN. Tetap ada persyaratan yang harus dipenuhi seperti kualifikasi yang disyaratkan oleh negara penerima dan kualifikasinya berbeda antara negara yang satu dengan negara lain. Pemahaman calon tenaga kerja tentang standar kualifikasi pekerja sangat diperlukan.

Kecenderungan selama ini adalah tenaga kerja Indonesia yang lebih aktif mengisi pasar tenaga kerja ASEAN meskipun kebanyakan bekerja pada sektor informal (lihat Tabel 2.) Hanya sedikit tenaga kerja asing dari ASEAN yang bekerja di Indonesia (lihat Tabel 3.). Dapat dikatakan, tenaga kerja Indonesia lebih agresif dalam mengisi permintaan tenaga kerja di ASEAN dibuktikan dengan jumlahnya paling banyak di ASEAN.

Alasan lain yang dapat menjelaskan MEA bukan sebagai ancaman bagi ketenagakerjaan Indonesia adalah rata-rata penghasilan tenaga kerja Indonesia masih kalah dengan beberapa negara anggota ASEAN yang lain. Dengan kondisi seperti itu Indonesia bukan menjadi tujuan utama bagi tenaga kerja ASEAN. Salah satu faktor pendorong bagi tenaga kerja untuk memutuskan bekerja di luar negeri salah satunya adalah mencari 
standar upah yang lebih tinggi. Negara yang menjadi tujuan utama tenaga kerja ASEAN tentunya adalah negara yang memiliki standar pengupahan yang relatif lebih tinggi dibandingkan negara ASEAN yang lain seperti Singapura, Malaysia, dan Thailand (lihat Tabel 5.).

Persaingan bebas tenaga kerja dalam kerangka MEA harus dilihat segi positifnya. Menurut perspektif liberalis, persaingan mendorong masing-masing pihak untuk meningkatkan daya saing. Tenaga kerja di ASEAN dihadapkan pada era persaingan bebas dalam pasar tenaga kerja ASEAN yang akan mendorong tenaga kerja dan juga pemerintah untuk meningkatkan daya saing tenaga kerja melalui program pelatihan ataupun pendidikan formal. Meningkatnya daya saing akan mendorong produktivitas tenaga kerja yang secara langsung juga akan meningkatkan pertumbuhan ekonomi di ASEAN.

\section{Kontestasi Geopolitik di ASEAN: Kolaborasi atau Kompetisi?}

Liberalisasi pasar tenaga kerja dapat dipandang dengan dua cara yang berbeda. Liberalisasi pasar tenaga kerja yang sedang terjadi di ASEAN seringkali dipandang sebagai ajang kompetisi. Para pembuat kebijakan di ASEAN saat ini sedang berlomba-lomba untuk meningkatkan daya saing tenaga kerja masing-masing. Peningkatan daya saing tenaga kerja menjadi kunci utama dari liberalisasi pasar tenaga kerja ASEAN.

Menurut perspektif liberalisme, kompetisi dalam pasar yang liberal adalah baik. Dengan adanya kompetisi masing-masing pihak berlomba untuk meningkatkan kualitas sehingga dapat meningkatkan produktivitas perekonomian. Para pemikir liberal percaya bahwa manusia dapat bersaing dengan cara yang konstruktif. Maksud dari konstruktif disini adalah bersaing secara adil dengan menggunakan cara yang tidak merugikan pihak lain.

Lain halnya dengan perspektif realis, kompetisi sering dipandang sebagai zero sum game. Peningkatan daya saing satu pihak sering diartikan melemahnya daya saing pihak yang lain. Dengan pandangan seperti ini, persaingan dapat mengarah kepada tindakan yang dapat merugikan pihak lain. Perspektif realis ini kemudian mempengaruhi para pembuat kebijakan untuk meningkatkan daya saing tenaga kerja lokal sembari membuat kebijakan untuk melemahkan daya saing tenaga kerja asing. Model kompetisi seperti ini dapat menghambat peningkatan produktivitas ASEAN sebagai basis produksi secara kolektif.

Apabila melihat karakteristik utama MEA yang sudah disusun oleh para pemimpin ASEAN, ada poin yang menjelaskan bahwa tujuan MEA adalah menjadi basis produksi dan pasar tunggal dan terintegrasi dalam perekonomian global. Arena persaingan negara-negara ASEAN seharusnya adalah arena perekonomian global bukan intraregional 
ASEAN sendiri. Apabila ASEAN mau kembali kepada jalur yang benar dalam pembentukan MEA, negara-negara ASEAN seharusnya mengedepankan kolaborasi daripada kompetisi antarnegara ASEAN sendiri.

Kolaborasi antarnegara ASEAN tentunya dapat meningkatkan daya saing tenaga kerja ASEAN secara kolektif agar mampu berkompetisi dalam pasar tenaga kerja global. Namun, kolaborasi antarnegara ASEAN masih minim khususnya dalam hal peningkatan daya saing tenaga kerja ASEAN. Negara-negara ASEAN terkesan lebih sibuk mempersiapkan tenaga kerjanya masing-masing untuk menghadapi era MEA. Dengan adanya kolaborasi atau kerjasama antarnegara dalam peningkatan daya saing tenaga kerja, maka liberalisasi pasar tenaga kerja bukan menjadi ancaman lagi buat masing-masing negara anggota ASEAN.

\section{Kesimpulan}

Tidak bisa dipungkiri bahwa sebagian besar masyarakat khawatir dengan arus bebas tenaga kerja pada era MEA. Penyebab utamanya adalah minimnya sosialisasi tentang MEA dan daya saing tenaga kerja Indonesia yang masih rendah. Tulisan ini berupaya untuk memberikan pemahaman bahwa liberalisasi tenaga kerja di ASEAN bukanlah menjadi ancaman bagi Indonesia. Arus bebas tenaga kerja yang dimaksud khusus untuk tenaga kerja terampil dan tetap masih ada regulasi yang mengatur perpindahan tenaga kerja ke lintas negara ASEAN. Sampai saat ini baru delapan profesi yang diatur dalam MRA. Profesi lain belum dapat menikmati kemudahan berpindah ke negara anggota ASEAN yang lain. Liberalisasi tenaga kerja membuat tenaga kerja untuk meningkatkan daya saing mereka dengan bantuan pemerintah. Hal ini dapat berdampak positif terhadap pertumbuhan ekonomi kawasan ini.

Tulisan ini juga berupaya untuk memberikan rekomendasi kepada para pemangku kepentingan untuk mempersiapkan tenaga kerja Indonesia agar lebih siap menghadapi MEA. Pertama, salah satu penyebab kekhawatiran masyarakat terhadap liberalisasi pasar tenaga kerja adalah minimnya sosialisasi kepada masyarakat terhadap MEA. Sosialisasi kepada calon tenaga kerja Indonesia (CTKI) yang akan bekerja di negara-negara ASEAN sangat perlu dilakukan. Informasi pasar kerja juga perlu diupayakan pemerintah supaya CTKI dapat mempersiapkan keterampilan yang sesuai dengan kualifikasi yang dibutuhkan oleh negara tujuan. Akan lebih baik lagi apabila informasi pasar kerja dapat diakses secara online.

Kedua, selain sosialisasi, daya saing juga menjadi kunci utama agar tenaga kerja Indonesia dapat diterima di negara anggota ASEAN yang lain. Pemerintah Indonesia perlu untuk membuat kebijakan yang 
dapat mendukung peningkatan daya saing melalui program pendidikan, pelatihan, dan program magang untuk meningkatkan pengalaman. Optimalisasi Balai Latihan Kerja Luar Negeri adalah hal yang dapat dilakukan oleh pemerintah.

Ketiga, menghindari membuat kebijakan yang cenderung bersifat proteksi seperti menerapkan persyaratan dan kualifikasi yang sulit dipenuhi oleh tenaga kerja asing. Hubungan internasional berifat resiprokal, apabila Indonesia mempersulit tenaga kerja asing untuk berkerja di Indonesia, ada kemungkinan tenaga kerja Indonesia juga akan diperlakukan sama.

Keempat, Indonesia sebagai salah satu negara terbesar dalam segi total PDB dan angkatan kerja perlu meningkatkan perannya sebagai negara yang berpengaruh di ASEAN dengan mendorong kerjasama antar negara ASEAN untuk meningkatkan kolaborasi antarnegara dalam mengembangkan pasar tenaga kerja ASEAN yang lebih baik. Kolaborasi yang dapat dilakukan misalnya kerjasama pelatihan untuk meningkatkan keterampilan tenaga kerja ASEAN.

\section{Daftar Pustaka}

ASEAN. (2014). ASEAN Community in Figures 2013. Jakarta: ASEAN Secretariat.

Badan Pusat Statistik. (2015) Statistik Mobilitas Penduduk dan Tenaga Kerja. Jakarta: Badan Pusat Statistik.

Balaam, D.N. dan Veseth, M. (2005) Introduction to International Political Economy Third Edition. New Jersey: Prentice Hall.

Ditjen Binapenta. (2014) Tenaga Kerja Asing Dalam Data dan Informasi. (Online) Ditjen Binapenta. Tersedia dalam:

(http://binapenta.naker.go.id/uploads/ebook/TKA_Data_dan_ Informasi_2014.pdf) [diakses 20 Maret 2016.]

Erianto, D. (2015) MEA, Antara Peluang dan Ancaman. (Online)Kompas, 1 Desember 2015, Tersedia dalam: (http://print.kompas.com/ baca/2015/12/01/MEA\%2c-Antara-Peluang-dan-Ancaman.) [diakses 20 Maret 2016.]

ILO dan ADB. (2014) ASEAN Community 2015: Managing Integration for Better Jobs and Shared Prosperity. Thailand: ILO dan ADB.

INFID. (2015) Prosiding Seminar Akhir Tahun 2015 Catatan INFID atas Kinerja ASEAN. Dalam: Seminar Akhir Tahun Catatan INFID Atas Kinerja ASEAN, Jakarta, 17 Desember 2015. Tersedia dalam: (http:// infid.org/wp-content/uploads/2016/01/Prosiding-ASEAN-adalahKita-Desember-2015.pdf.) [diakses 20 Maret 2016.]

Mahbubani, K. (2013) The Great Convergence. New York: PublicAffairs.

Plummer, M.G., Petri, P.A., dan Zhai, F. (2014) Assesing the Impact of ASEAN Economic Integration on Labour Markets. ILO Asia-Pacific 
Working Paper Series.

Sugiyarto, G. dan Agunias, D.R. (2014) A 'Freer' Flow of Skilled Labour within ASEAN: Aspirations, Opportunities and Challenges in 2015 and Beyond. Issue in Brief: A Joint Series of the IOM Regional Office for Asia and the Pacific and the Migration Policy Institute, Issue No. 11, Desember 2014.

UNDP. (2014) Key to HDI Countries and Ranks. (Online) UNDP. Tersedia dalam: (http://hdr.undp.org/sites/default/files/ranking.pdf) [diakses pada 21 Maret 2016.]

Widianto, S. (2014) Jelang MEA 2015 Baru 2,1 Juta Tenaga Kerja Miliki Sertifikasi Kompetensi Kerja. (Online) Pikiran Rakyat, 1 November 2014. Tersedia dalam: (http://www.pikiran-rakyat. com/ekonomi/2014/11/01/303004/baru-21-juta-tenaga-kerja-milikisertifikasi-kompetensi-kerja.) [diakses 20 Maret 2016.] 